\title{
Gene signature for prognosis in comparison of Pancreatic cancer patient with diabetes and non-diabetes
}

\author{
Yang Mingjun $^{1}$, Song Boni ${ }^{\text {Corresp., } 1}{ }^{,}$Liu Juxiang ${ }^{2}$, Bing Zhitong ${ }^{3}$, Wang Yonggang $^{4}$, Yu Linmiao ${ }^{1}$ \\ ${ }^{1}$ School of Life Science and Engineering, Lanzhou University of Technology, Lanzhou, Gansu, China \\ 2 Gansu Key Laboratory of Endocrine and metabolism, Department of Endocrinology, Gansu Provincial People's Hospital, Lanzhou, Gansu, China \\ 3 Lanzhou University, Lanzhou, China \\ 4 Lanzhou University of Technology, Windsor University School of Medicine, Lanzhou, Gansu, China \\ Corresponding Author: Song Boni \\ Email address: lut8866@163.com
}

Background Pancreatic cancer (PC) has much weaker prognosis, which can be divided into diabetes and non-diabetes. PC patients with diabetes mellitus will have more opportunities for physical examination due to diabetes, while pancreatic cancer patients without diabetes tend to have higher risk. Identification of prognostic markers for diabetic and non-diabetic pancreatic cancer can improve the prognosis of patients with both types of pancreatic cancer. Methods Both types of PC patients perform differently at the clinical and molecular levels. The Cancer Genome Atlas (TCGA) is employed in this study. The gene expression of the PC with diabetes and non-diabetes is used for predicting their prognosis by LASSO (Least Absolute Shrinkage and Selection Operator) Cox regression. Furthermore, the results are validated by exchanging gene biomarker with each other and verified by independent Gene Expression Omnibus (GEO) and international cancer genome consortium (ICGC). The prognostic index (PI) is generated by a combination of genetic biomarkers that are used to rank the patient's risk ratio. Survival analysis is applied to test significant difference between high-risk group and low-risk group. Results An integrated gene prognostic biomarker consisted by 14 low-risk genes and 6 high-risk genes in PC with non-diabetes. Meanwhile, and another integrated gene prognostic biomarker consisted by 5 low-risk genes and 3 high-risk genes in PC with diabetes. Therefore, the prognostic value of gene biomarker in PC with non-diabetes and diabetes are all greater than clinical traits $(H R=1.102$, P-value <0.0001; $H R=1.212$, P-value $<0.0001)$. Gene signature in PC with nondiabetes was validated in two independent datasets Conclusions The conclusion of this study indicated that the prognostic value of genetic biomarkers in PCs with non-diabetes and diabetes. The gene signature was validated in two independent database. Therefore, this study is expected to provide a novel gene biomarker for predicting prognosis of PC with non-diabetes and diabetes and improving clinical decision. 


\section{Gene Signature for Prognosis in Pancreatic Cancer patient with}

\section{diabetes and Non-diabetes}

3 Mingjun Yang ${ }^{1 *}$, Boni Song ${ }^{1}$, Juxiang Liu $^{2 *}$, Zhitong Bing ${ }^{3,4}$, Yonggang Wang ${ }^{1}$, Linmiao Yu ${ }^{1}$

4 1. School of Life Science and Engineering, Lanzhou University of Technology, Lanzhou 730050,

5 Gansu, China.

6 2. Department of Endocrinology, Gansu Provincial People's Hospital, Gansu Key Laboratory of

7 Endocrine and metabolism, 204 Dong gang West Road, Lanzhou 730000, China.

8 3. Evidence Based Medicine Center, School of Basic Medical Science of Lanzhou University,

9 Lanzhou 730000, China.

10 4. Institute of Modern Physics of Chinese Academy of Sciences, Lanzhou 730000, China.

11 Mingjun Yang and Juxiang Liu contributed equally to this study

12 Corresponding to: yangmj@lut.cn or bingzt@impcas.ac.cn

13 Number of figures: 4

14 Number of tables: 4

15 Number of supplementary files: 2

16 Supplementary Figure 1. The Cross-validation error curve of pancreatic cancer with diabetes.

17 Supplementary Figure 2. The Cross-validation error curve of pancreatic cancer with non-diabetes

18 Supplementary File 1. Raw data and code for gene expression analysis 


\section{Abstract}

\section{Background}

22 Pancreatic cancer (PC) has much weaker prognosis, which can be divided into diabetes and non23 diabetes. PC patients with diabetes mellitus will have more opportunities for physical examination 24 due to diabetes, while pancreatic cancer patients without diabetes tend to have higher risk. Identification of prognostic markers for diabetic and non-diabetic pancreatic cancer can improve 26 the prognosis of patients with both types of pancreatic cancer.

\section{Methods}

28 Both types of PC patients perform differently at the clinical and molecular levels. The C ancer Genome Atlas (TCGA) is employed in this study. The gene expression of the PC with diabetes and non-diabetes is used for predicting their prognosis by LASSO (Least A bsolute Shrinkage and Selection Operator) Cox regression. Furthermore, the results are va lidated by exchanging gene biomarker with each other and verified by independent Gene Expression Omnibus (GEO) and international cancer genome consortium (ICGC). The pro gnostic index (PI) is generated by a combination of genetic biomarkers that are used to rank the patient's risk ratio. Survival analysis is applied to test significant difference betw een high-risk group and low-risk group.

\section{Results}

An integrated gene prognostic biomarker consisted by 14 low-risk genes and 6 high-risk genes in

PC with non-diabetes. Meanwhile, and another integrated gene prognostic biomarker consisted by

405 low-risk genes and 3 high-risk genes in PC with diabetes. Therefore, the prognostic value of 41 gene biomarker in $\mathrm{PC}$ with non-diabetes and diabetes are all greater than clinical traits $(\mathrm{HR}=1.102$, 42 P-value $<0.0001 ; \mathrm{HR}=1.212$, $\mathrm{P}$-value $<0.0001)$. Gene signature in $\mathrm{PC}$ with non-diabetes was 43 validated in two independent datasets

\section{Conclusions}

45 The conclusion of this study indicated that the prognostic value of genetic biomarkers in PCs with non-diabetes and diabetes. The gene signature was validated in two independent database.

47 Therefore, this study is expected to provide a novel gene biomarker for predicting prognosis of PC 
48 with non-diabetes and diabetes and improving clinical decision.

49 Keywords: PC, diabetes, LASSO Cox regression, prognosis index 


\section{Introduction}

51 PC is an aggressive cancer of the digestive system, which is becoming a serious health problem

52 worldwide. Overall survival for patients with pancreatic cancer is poor, mainly due to a lack of

53 biomarkers to enable early diagnosis and a lack of prognostic markers that can inform decision-

54 making, facilitating personalized treatment and an optimal clinical outcome (1). In most cases,

55 type-II diabetes frequently occurs in patients with PC .Thus, it is considered to be an important

56 risk factor for malignancy of PC (2). However, non-diabetes PC patients have no early diagnosis

57 indicator, which makes it more difficult to diagnose. In addition, PC with diabetes and without

58 diabetes are very different in histopathology (3) and molecular levels. Currently, many studies do

59 not consider the difference between PC with diabetes and non-diabetes. They just considered that

60 diabetes was a risk factor in PC development (4). With the deeper understanding of the relationship

61 between PC patient with diabetes and non-diabetes, recent data suggests that diabetes and altered

62 in glucose metabolism are the consequence of PC, and yet, the clinical presentation of the altered

63 glucose metabolism in these patients vary considerably (5). So, PC patients with diabetes and non-

64 diabetes may represent two types of PC. Therefore, we predict that PC patients with diabetes and

65 non-diabetes are also different in their prognostic biomarkers. The different prognostic biomarkers

66 indicate that they should be treated respectively via their own different ways.

67 Generally, patients with diabetes have more opportunities to detect the potential risk of pancreatic 68 cancer, while patients without diabetes often lack indicators for early diagnosis and miss the best

69 opportunity for pancreatic cancer treatment. Furthermore, good prognostic markers can also be

70 targeted at two types of pancreatic cancer patients to propose better treatment options, improve the 71 prognosis.

72 In this study, The Cancer Genomic Atlas (TCGA) database, Gene Expression Omnibus (GEO)

73 database and international cancer genome consortium (ICGC)were employed to investigate and

74 validate gene biomarker for prognosis in $\mathrm{PC}$ with or without diabetes. By characterizing genetic 
75 alterations, TCGA project has provided a large number of comprehensive genomic cancer data 76 and corresponding clinical data that we can be used to figure out the relationship between them, 77 which allows us to understand PC better and more accurate. However, high through-put genomic 78 data (microarray or High seq V2) may encounter the problem in statistics which called "curse of 79 dimensionality"'(6). Due to this problem, ordinary regression is subject to over-fitting and instable coefficients and stepwise variable selection methods do not scale well (7). Therefore, the least 81 absolute shrinkage and selection operator (LASSO) method is employed to resolve this problem $82(8,9)$. Through adjusting the coefficient of Cox regression, LASSO can penalize the regression in 83 high dimensionality and collinearity to solve "curse of dimensionality"'(10,11). Least Absolute

84 Shrinkage and Selection Operator (LASSO) regression and a hybrid of these (elastic net regression); all three methods are based on penalizing the L1 norm, the L2 norm, and both the L1 norm and L2 norm with tuning parameters. Although the traditional Cox proportional hazards model is widely used to discover cancer prognostic factors, it is not appropriate for the genomic setting due to the high dimensionality and collinearity. Several groups have proposed to combine the Cox regression model with the elastic net dimension reduction method to select survivalcorrelated genes within a high-dimensional expression dataset and have made available the associated computation procedures. Many studies have adopted elastic-net regression to screen genes, in order to predict survival of patients. In the current study, we are going to subject the integrated mRNA and clinical factors profiles of PC patients, aiming to identify and analyze gene biomarker that can predict the overall survival (OS) in the diabetes and non-diabetes of PC patients by LASSO.

96 Recently, many studies employed TCGA (TCGA-PAAD) and GEO dataset (GSE62452) to 97 identify useful gene biomarker which can predict prognosis in many various cancer patients 98 (12,13). In this study, ICGC dataset was also employed to validate prognostic gene signature. Along with the increasing genomic data of PC patients, lots of corresponding studies begin to analyze the genomic data and try their best to explore interesting and meaningful but extremely 
101 difficult problems $(14,15)$.

\section{Materials and Methods}

\section{Information of Patients}

104 All related studies about diabetic and non-diabetic patients with PC were identified and collected

105 by carefully searching from the online TCGA (TCGA: GDC TCGA Pancreatic Cancer)

106 databases (http://tcga-data.nci.nih.gov/tcga/). The following combination of keywords was

107 simultaneously applied for the literature search according to the requirement of this study

108 'pancreatic cancer' or 'PC' or 'pancreatic tumor' or 'pancreatic malignancy' and 'diabetes' and

109 'non-diabetes'. In addition, the following research feature criteria are used to further improve

110 and screen the desired search samples: (1) researches that concentrated on patients with diabetes

111 and non-diabetes were selected; (2) survival time involved of patients was more than 30 days; (3)

112 patients who didn't receive any adjuvant therapy before. (4) all tissues that were from patients

113 must be the primary tumor. After filtering and screening the data by these above criteria, 136

114 samples were selected from TCGA databases, which included 99 non-diabetic patients and 37

115 diabetic patients with PC.

\section{RNA data Gathering and Filtering}

117 The data of mRNA expression was downloaded from TCGA database. And the IIIumina HiSeq

118 RNASeqV2 platform is selected.

\section{Clinical factors and survival analysis}

120 Clinical factors for the both diabetic and non-diabetic patients with PC are listed exhaustively in

121 supplementary table1. For the correlation between RNA expression and OS was carried out by

122 forthputting univariate Cox regression (the two-sided log-rank test). In the present meta-analysis,

123 HRs and corresponding 95\% CIs were combined to estimate the value of cancer prognosis. The

124 hazard ratio (HR) was calculated from $\exp (\beta)$ and $\beta$ was the coefficient from Cox regression.

125 Clinical variables from univariate Cox proportional hazards regression $\mathrm{P}$-value $\leq 0.05$ were 
126 regarded as an important indicator of diabetic and non-diabetic patient prognosis.

\section{The Expression of mRNA associated with Survival Analysis}

128 The relationship between patient survival and mRNA expression was analyzed through drawing 129 on the univariate Cox proportional hazard regression. The null-selected RNA is calculated again 130 and again. $\mathrm{P}$-value $\leq 0.05$ screened for mRNA $(\mathrm{P} \leq 0.05)$. In normal conditions, RNAs that had a

$131 \mathrm{HR}>1$ and $\mathrm{P}$ value $\leq 0.05$ were considered to be a risky gene while $\mathrm{HR}<1$ is seen as an improved

132 low-risky gene. In diabetic patients with PC, we reached a conclusion that 64 mRNAs are 133 significantly associated with overall survival time $(\mathrm{p}<0.05)$ by univariate Cox regression. In non134 diabetic patients with PC, we acknowledged that 1,559 mRNAs are obvious significantly 135 associated with overall survival time $(\mathrm{p}<0.05)$. In data of high dimension gene expression, the 136 coefficients $(\beta)$ of Cox regression model needs to be penalized in order that it can fit better and 137 minimize errors as much as possible. Therefore, elastic net-regulated Cox regression method is 138 applied to calculate the results from univariate Cox regression. The penalized log-likelihood 139 function is defined as following:

$$
l_{p}(\beta, X)=l(\beta, X)-\lambda \sum_{j=1}^{p}\left|\beta_{j}\right|
$$

141 With the value of $\lambda$ increasing, value of $\sum_{j=1}^{p}\left|\beta_{j}\right|$ would be decreased. Then, some coefficients $(\beta)$

142 of RNAs would be changed into 0 . This result was analyzed by selecting the LASSO-adjusted Cox

143 regression coefficient $\neq 0$ mRNA. These steps are carried out by $\mathrm{R}$ package "glmnet". Finally, we 144 obtained eight mRNAs in diabetic patient with PC and 20 mRNAs in non-diabetic patients with 145 PC.

\section{Prognosis index construction}

147 PI is calculated from linear combination of candidate RNAs and their expression for each PC 148 patient. We defined a weighted prognostic index (WPI) (16) for integrating indicators of RNAs 149 for each PC patient, as following:

$$
\mathrm{PI}=\sum(\beta i * V i)
$$




$$
\mathrm{WPI}=\frac{P I-\text { mean }(P I)}{S D(P I)}
$$

152 Where $\beta_{i}$ represents the coefficient in Cox regression of the $i$ th variable. And $V_{i}$ signifies the value

153 of the $i$ th variable. Mean (PI) and SD (PI) stand for the mean value and standard deviation of the

154 PI, respectively. Where $V_{i}$ is the expression value of each mRNA (log2-transformed expression

155 value) and $\beta_{i}$ is the LASSO regulated Cox proportional hazards regression coefficient of the $i$ th

156 RNA or clinical traits.

\section{Risk stratification and ROC curves}

158 The capacity of the integrated RNA and clinical model to predict clinical outcome was evaluated

159 by comparing the analysis of area under curve (AUC) of the receiver operation characteristic 160 (ROC) curves. AUC for the ROC curve was applied to the "survival ROC" package in R 161 software(17). The higher AUC is considered as a better model performance and range of AUC

162 value is from 0.5 to 1 . The AUC range from $0.80-0.90$ is treated as good performance. And the

163 range from $0.90-1.00$ was considered to be excellent performance. The risk of patient group was

164 classified into two groups based on the median of WPIs: high-risk and a low-risk. Survival analysis

165 is forthputting Kaplan-Meier curves. Statistical analysis and graph in this study were performed

166 using the software of R software(18), version 3.2.4 and Bioconductor, version 2.15 (19).

167 Gene Ontology and Pathway Enrichment

168 Gene ontology (GO) functional enrichment analysis was performed to RNAs which classified as 169 low-risk and high-risk group by making use of the online tool of the DAVID (version 6.8). We

170 chose "Homo sapiens" as the background in order to search terms "GO_TERM_BP_FAT" for

171 further analysis. And these genes are also enriched in Kyoto Encyclopedia of Genes and Genomes

172 (KEGG) pathway for analysis(20).

\section{Validation data of patient information collection}

174 In this study, we selected two independent datasets to validation. An independent mRNA

175 expression data of PC patients with 65 PC patients was downloaded from Gene Expression

176 Omnibus(GEO: GSE62452) database (https://www.ncbi.nlm.nih.gov/geo/). The clinical traits and 
177 expression were all downloaded from GSE62452. And the mRNA expression data were generated

178 by Affymetrix Human Genome U133A Array. Data from GEO was analyzed using the updated 179 July 26, 2018.

180 Another database was downloaded from ICGC database (https://dcc.icgc.org/). We selected

181 Pancreatic Cancer - AU data for further validation. This dataset included 92 PC patients with

182 RNAseq and clinical information. The genomic data of this dataset uses the technology of next

183 generation sequencing. This gene data contained 56,026 RNAs and 92 patients' follow-up data.

184 We extracted gene signature from 56,026 RNAs for verification prognosis. (All raw data and code

185 was listed in supplementary file 1)

\section{Results}

\section{Clinical traits}

188 In the TCGA PC cohort of the 136 patients, 99 patients are non-diabetic PC patients and 37 patients

189 are diabetic PC patients. We calculated the clinical factors by adopting univariate survival analysis

190 and multivariable Cox regression analysis. We selected nine clinical variables including age,

191 gender, tumor status, alcohol history, history of chronic pancreatitis, number of lymph nodes

192 positive, maximum tumor dimension, neoplasm histologic grade and pathologic stage. And these

193 data are summarized in table1. In pancreatic patients without a diabetes cohort, tumor status was

194 significantly associated with overall survival by long-rank and multivariate Cox regression

195 analysis. This result indicated that tumor status is an independent factor correlated with overall

196 survival. In pancreatic patients with diabetes cohort, gender is significantly associated with overall

197 survival time. But this factor is not an independent factor by multivariate Cox regression analysis

198 (Figure 1, Table 1).

199 Gene signature analysis in PC cohort

200 By analyzing of non-diabetes and diabetes PC patients through LASSO Cox regression and

201 multivariate Cox regression, we have obtained 20 mRNAs and 8 mRNAs biomarkers, respectively, 
202 which were significantly associated with overall survival. Among these genes, the values of HR $<$

2031 and $\mathrm{P}$ value $<0.01$ were considered as protective RNAs and otherwise the values of HR $>1$ were

204 risky RNAs (Table 2, 3). And the graph for elastic net Cox regression is listed in supplementary

205 file (supplementary 1 and supplementary 2).

206 The PI was significantly associated with pancreatic patient survival. After normalized PI to WPI,

207 the median value of WPI is acted as cutoff threshold to classify low-risk and high-risk patient

208 cohort (Figure 1).

209 Validation of the prognostic gene signature

210 The results were employed in two different ways to verify its stability and reliability. Firstly, we

211 used the gene biomarker in PC patients with diabetes ( 8 mRNAs) to test the survival curve in PC

212 patients with non-diabetes. Secondly, we used the gene biomarker in PC patients with non-diabetes

213 (20 mRNAs) to swap above calculation.

214 The validated results showed that the gene biomarker in two groups performed poor result after

215 exchange (Figure 2). The results indicated that the gene biomarker in different groups has

216 specificity in each condition.

217 For validation result, independent mRNA expression data and corresponding clinical information

218 of PC patient with non-diabetes is downloaded from GEO database to estimate the reproducibility

219 and robustness of the results from TCGA database.

220 Gene Ontology Enrichment

221 The Database for Annotation, Visualization and Integrated Discovery (DAVID) v6.8 was

222 employed to discover the function of genes both in PC patient with diabetes and non-diabetes. The

223 eight genes in $\mathrm{PC}$ with diabetes were associated with regulation of transcription with a Benjamini-

224 Hochberg correction P-value $<0.05$. And many genes had DNA binding function. For 20 genes

225 identified in PC without diabetes were not enriched statistically significant association.

226 Comparison of clinical traits and gene biomarker for predicting prognosis

227 We integrated clinical traits that significantly associated with survival and PI of gene biomarker 
228 that significantly associated with survival to analyze the pancreatic cancer in diabetic and non-

229 diabetic individuals. After multivariate Cox regression analysis, the results showed that PI of gene

230 biomarker performed greatest P-value (Table 4). We filtered the clinical factors that significantly

231 associated with survival by log-rank test into integrative model. In PC with non-diabetes, tumor

232 status, number of lymph nodes positive, stage G2, G3 and G4 were significantly associated with

233 survival (Table 1). And in PC with diabetes, gender, stage G2 and G3 were significantly associated

234 with survival by log-rank test (Table 1).

235 From the table 4, we find PI of gene biomarker have smallest P-value after multivariable Cox

236 regression. Although HR is not the highest among clinical traits, P-value is the smallest. Besides,

237 we can find that tumor status is another significant risk factor in PC with non-diabetes.

238 Independent data validation for $\mathrm{PC}$ with non-diabetes

239 For further validation result, independent mRNA expression data and corresponding clinical

240 information of PC patient with non-diabetes is downloaded from GEO database (GSE62452) to

241 estimate the reproducibility and robustness of the results from TCGA database. The results showed

242 that the gene signature from TCGA data could be validated in GEO database $(n=65)$. PI was

243 calculated from gene signature can effectively predict survival of PC with non-diabetes. The

244 median of PI value divided 65 patients into high-risk group and low-risk group (HR=3.006, P-

245 value $<0.001$ ). And results of ROC showed that $\mathrm{AUC}=0.828$. The results indicated that the gene

246 signature from TCGA could be validated in independent dataset (Figure 3).

247 Pancreatic cancer data was downloaded from ICGC database. This data included 92 patients with

248 genomic data and clinical information. The gene signature was matched ICGC database and

249 constructed PI model. The results showed that the PI from gene signature can divided patients into

250 high-risk and low-risk groups significantly $(\mathrm{HR}=2.84$, P-value $<0.001)$ in ICGC data. $\mathrm{ROC}$ showed

251 that $\mathrm{AUC}=0.74$, which indicated that the gene signature also validated in ICGC and predict

252 performance well in 3 years (Figure 4). 


\section{Discussion}

254 PC patients showed different prognostic gene signature in diabetes and non-diabetes. Identification

255 special gene signature in different types of PC patients would provide precise medicine for 256 different patients. We identified and verified specific high-risk genes for PC patients without 257 diabetes. And these genes have not been reported before. These gene targets may be potential 258 therapeutic targets for pancreatic cancer.

259 In this study, we proposed two classes of gene biomarkers in PC patients with and without diabetes 260 which can guide us to predict PC patient survival better and more accurate. To a large extent, PC 261 patients with and without diabetes have quite different gene biomarker for predicting prognosis. 262 After a series of studies, we not only find that genes candidate in both PC patient groups have no 263 overlapping but also figure out that gene biomarker in non-diabetes PC patients is validated by 264 GEO and ICGC datasets. The result indicated that the two sets of gene biomarker in both groups 265 have been very specified. Therefore, they have their own gene biomarker for predicting their 266 prognosis. Because the differences between diabetic and non-diabetic pancreatic cancer patients 267 are often ignored, we only got two types of patients in TCGA database. Other validation databases 268 contained only non-diabetic patients. Furthermore, non-diabetic patients with pancreatic cancer 269 are more likely to be ignored in the diagnosis, leading to a higher risk of such patients. Thus, we

270 validated gene biomarker in non-diabetes PC patients in more datasets. Although a large number 271 of studies have reported some biomarkers in PC patients, many genes have been identified 272 primarily in PC patients without diabetes. We identified and compared the gene signature that 273 predict both types of PC patients. And many genes have not been reported yet so far. Among the 274 high risk prognostic genes, CRCT1, MUC20, RTP1, C10orf111, SPACA5 and FZD10 have high 275 level of HR. MUC20, FZD 10 have been identified in PC patients $(21,22)$ and these two genes play 276 a vital role in two important pathways associated with cancer. MUC20 is involved in MET

277 (Mesenchymal-Epithelial transitions) process which is a common process in many tumors (23). 
278 And it may regulate MET signaling cascade. It appears to decrease hepatocyte growth factor 279 (HGF)-induced transient MAPK activation (24). FZD10 is associated with WNT signaling 280 pathway which is implicated in embryogenesis as well as in carcinogenesis (25). Other genes were 281 not reported in PC patients, but only SPACA5 is reported in bladder cancer (26). Although many 282 genes have not been reported before, we find that these combinations of these genes can greatly 283 distinguish high-risk and low-risk PC patients with non-diabetes. In addition, these genes were 284 validated in an independent GEO database and ICGC database. The results of GSE62452 in the

285 GEO database indicated that these genes were stably expressed and the gene biomarker could 286 distinct between high-risk and low-risk gene greatly.

287 The gene biomarker in PC patients with diabetes, three genes are high-risk genes. We can find that 288 the production of these three genes (ZNF793, GBP6, FOSL1) are binding function proteins. Thus, 289 we infer that they are all transcription factors. Of the three genes, FOSL1 has been reported to be 290 closely associated with $\mathrm{PC}(27-29)$. But these studies have not reported that this high-risk gene is 291 associated with PC with diabetes yet. Only one study reported that FOSL1 is closely associated 292 with diabetes mellitus (30). And this gene has not been identified in PC with non-diabetes. GBP6 293 is reported in diabetes(31) but is not reported in PC patients with diabetes. ZNF793 is not identified 294 in both PC and diabetes. Thus, we infer that the gene is a potential risk factor in PC patients with 295 diabetes.

296 Through multivariate Cox regression analysis, it is interesting to note that tumor status is an

297 independent predictor of prognosis in non-diabetes PC patients. Gender is an independent predictor 298 of prognosis in patients with diabetes in PC. Tumor status is a vital clinical factor for predicting 299 the prognosis in many cancers.

300 From the results, we find that there was no overlapping of both groups. Thus, we conclude that 301 two types of PC vary greatly at the molecular level. Prognostic gene signature in non-diabetes PC 302 patients showed robustness among two datasets (GEO and ICGC). Many genes have not reported 303 in publication and we hope that these genes can predict prognosis for improving clinical decision. 


\section{Conclusion}

305 Pancreatic cancer patients with diabetes and without diabetes have different gene signature for

306 predicting their respective prognosis. The results indicated that Gene signature of pancreatic cancer

307 patients without diabetes has been validated in two independent datasets. Thus, the different gene 308 marker might be as an useful tool for the clinical decision in future.

\section{Acknowledgement}

310 This project was supported by the National Natural Science Foundation of China (Grant No. $31181660581)$.

\section{Ethical Policies and Standards}

313 Conflict of Interest: The authors declare that they have no conflict of interest.

314 Ethical approval: This article does not contain any studies with human participants or animals

315 performed by any of the authors.

316 


\section{Reference}

318 1. Siegel RL, Miller KD, Jemal A. Cancer statistics, 2016. Ca A Cancer Journal for

319 Clinicians. 2016;66(1):10-29.

320 2. Huxley R, Ansarymoghaddam A, González ABD, Barzi F, Woodward M. Type-II diabetes

321

322 and PC: a meta-analysis of 36 studies. Br. J. Cancer. 2005;92(11):2076-2083.

323

3. Girelli CM, Reguzzoni G, Limido E, Savastano A, Rocca F. Pancreatic carcinoma: differences between patients with or without diabetes mellitus. Recenti Prog. Med.

325 1995;86(4):143-146.

326

327

4. Fisher WE. Diabetes: Risk Factor for the Development of PC or Manifestation of the Disease? World J. Surg. 2001;25(4):503-508.

328

5. Yalniz M, Pour PM. Diabetes mellitus: a risk factor for PC? Langenbeck's Archives of

329 Surgery. 2005;390(1):66-72.

6. Mramor M, Leban G, Ar J, Zupan B. Conquering the Curse of Dimensionality in Gene

330

331

332

333 Expression Cancer Diagnosis: Tough Problem, Simple Models. Paper presented at: Artificial Intelligence in Medicine, Conference on Artificial Intelligence in Medicine, Aime 2005, Aberdeen, Uk, July 23-27, 2005, Proceedings2005.

334

335

336

337

338

7. Jr HF, Lee KL, Mark DB. Multivariable prognostic models: issues in developing models,
evaluating assumptions and adequacy, and measuring and reducing errors. Stat. Med. 1996;15(4):361-387.

8. Wang L, You Y, Lian H. Convergence and sparsity of Lasso and group Lasso in high-

339

9. Simon N, Friedman J, Hastie T, Tibshirani R. Regularization Paths for Cox's Proportional

339

340

10. Tibshirani R, Bien J, Friedman J, et al. Strong rules for discarding predictors in lasso - type

341 problems. Journal of the Royal Statistical Society. 2012;74(2):245.

342 11. Friedman J, Hastie T, Tibshirani R. Regularization Paths for Generalized Linear Models via Coordinate Descent. Journal of Statistical Software. 2010;33(1):1.

12. Bing Z, Tian J, Zhang J, Li X, Wang X, Yang K. An Integrative Model of miRNA and mRNA Expression Biomarker for Patients of Breast Invasive Carcinoma with Radiotherapy Prognosis. Cancer Biother. Radiopharm. 2016/09// 2016;31(7):253-260.

13. Yang R, Jie X, Deng D, et al. An integrated model of clinical information and gene expression for prediction of survival in ovarian cancer patients. Translational Research the Journal of Laboratory \& Clinical Medicine. 2016;172:84-95.

14. Gore J, Craven KE, Wilson JL, et al. TCGA data and patient-derived orthotopic xenografts highlight PC-associated angiogenesis. Oncotarget. 2015;6(10):7504.

15. Craven KE, Gore J, Wilson JL, Korc M. Angiogenic gene biomarker in human PC correlates with TGF-beta and inflammatory transcriptomes. Oncotarget. 2015;7(1):323- 
354341.

355 16. Xiong J, Bing Z, Su Y, Deng D, Peng X. An integrated mRNA and microRNA expression 356 biomarker for glioblastoma multiforme prognosis. PLoS One. 2014;9(5):e98419-e98419.

357 17. Heagerty PJ, Lumley T, Pepe MS. Time-Dependent ROC Curves for Censored Survival 358 Data and a Diagnostic Marker. Biometrics. 2000;56(2):337-344.

359 18. Ihaka R, Gentleman R. R: A Language for Data Analysis and Graphics. Journal of 360

361

362

363

19. Gentleman RC, Carey VJ, Bates DM, et al. Bioconductor: open software development for computational biology and bioinformatics. Genome Biol. 2004;5(10):R80.

364

20. Aoki KF, Kanehisa M. Using the KEGG Database Resource. Current Protocols in

365 Bioinformatics: John Wiley \& Sons, Inc.; 2002.

366

367

21. Lee J, Lee J, Yun JH, Jeong DG, Kim JH. DUSP28 links regulation of Mucin 5B and Mucin 16 to migration and survival of AsPC-1 human PC cells. Tumour Biology the Journal of the International Society for Oncodevelopmental Biology \& Medicine. 2016:1-

368 10.

369

22. Kirikoshi H, Katoh M. Expression of WNT7A in human normal tissues and cancer, and

370

371

23. Spaderna S, Schmalhofer O, Hlubek F, Jung A, Kirchner T, Brabletz T. Epithelial-

372

373

374

24. Higuchi T, Orita T, Katsuya K, et al. MUC20 suppresses the hepatocyte growth factor-

375

376

377

25. Terasaki H, Saitoh T, Shiokawa K, Katoh M. Frizzled-10, up-regulated in primary

378

379

380

381

382

383

384

385

386

387

388

389 mesenchymal and mesenchymal-epithelial transitions during cancer progression. Verh. Dtsch. Ges. Pathol. 2007;91(91):21-28.

induced Grb2-Ras pathway by binding to a multifunctional docking site of met. Mol. Cell. Biol. 2004;24(17):7456. colorectal cancer, is a positive regulator of the WNT - beta-catenin - TCF signaling pathway. Int. J. Mol. Med. 2002;9(2):107.

26. Zhang, Yan, Guo, Chen, Chen, Tang. Expression profile ofSPACA5/Spaca5in spermatogenesis and transitional cell carcinoma of the bladder. Oncol. Lett. 2016;12(5):3731-3738.

27. Vallejo A, Valencia K, Vicent S. All for one and FOSL1 for all: FOSL1 at the crossroads of lung and PC driven by mutant KRAS. Molecular \& Cellular Oncology. 2017;4(3):e1314239.

28. Vallejo A, Perurena N, Guruceaga E, et al. An integrative approach unveils FOSL1 as an oncogene vulnerability in KRAS-driven lung and PC. Nature communications. 2017;8:14294.

29. Sahin F, Qiu W, Wilentz RE, Iacobuziodonahue CA, Grosmark A, Su GH. RPL38, FOSL1, and UPP1 Are Predominantly Expressed in the Pancreatic Ductal Epithelium. Pancreas. 2005;30(2):158-167.

391

392

30. Portal-Núñez S, Lozano D, de Castro LF, de Gortázar AR, Nogués X, Esbrit P. Alterations 
393

394

395

396

397

398

399 of the Wnt/beta-catenin pathway and its target genes for the $\mathrm{N}$ - and C-terminal domains of parathyroid hormone-related protein in bone from diabetic mice. FEBS Lett. 2010;584(14):3095.

31. O'Tierney PF, Lewis RM, Mcweeney SK, et al. Immune Response Gene Profiles in the Term Placenta Depend Upon Maternal Muscle Mass. Reprod. Sci. 2012;19(10):1041. 


\begin{tabular}{|c|c|c|c|c|c|c|}
\hline \multicolumn{4}{|c|}{ Non-diabetes PC $(\mathrm{n}=99)$} & \multicolumn{3}{|c|}{ Diabetes PC $(n=37)$} \\
\hline Factors & Death/patients & Log-rank & $\begin{array}{l}\text { Multivariat } \\
\text { e Cox P }\end{array}$ & Death/patients & Log-rank & $\begin{array}{l}\text { Multivariate } \\
\text { Cox P }\end{array}$ \\
\hline Age & & 0.051 & 0.496 & & 0.959 & 0.446 \\
\hline$<=64$ & $22 / 52$ & & & $7 / 16$ & & \\
\hline$>64$ & $31 / 47$ & & & $8 / 21$ & & \\
\hline Gender & & 0.402 & 0.172 & & $0.001 *$ & 0.340 \\
\hline Female & $27 / 50$ & & & $7 / 12$ & & \\
\hline Male & $26 / 49$ & & & $8 / 25$ & & \\
\hline Tumor Status & & $9.3 \mathrm{e}-06^{*}$ & $0.0004^{*}$ & & $0.005^{*}$ & 0.513 \\
\hline With Tumor & $42 / 57$ & & & $10 / 17$ & & \\
\hline Tumor Free & $6 / 35$ & & & $2 / 15$ & & \\
\hline Unknown & $7 / 7$ & & & $3 / 5$ & & \\
\hline Alcohol history & & 0.537 & 0.144 & & 0.599 & 0.638 \\
\hline Yes & $40 / 68$ & & & $10 / 27$ & & \\
\hline No & $12 / 39$ & & & $5 / 10$ & & \\
\hline Unknown & $1 / 2$ & & & - & & \\
\hline $\begin{array}{l}\text { History of } \\
\text { chronic } \\
\text { pancreatitis }\end{array}$ & & 0.597 & 0.998 & & 0.273 & 0.998 \\
\hline Yes & $4 / 8$ & & & $3 / 4$ & & \\
\hline No & $48 / 86$ & & & $10 / 31$ & & \\
\hline Unknown & $1 / 5$ & & & $2 / 2$ & & \\
\hline $\begin{array}{l}\text { Number of } \\
\text { lymph nodes } \\
\text { positive by he }\end{array}$ & & $0.003 *$ & 0.396 & & 0.480 & 0.533 \\
\hline$<3$ & $22 / 52$ & & & $7 / 20$ & & \\
\hline$>=3$ & $30 / 45$ & & & $8 / 16$ & & \\
\hline $\begin{array}{l}\text { Maximum } \\
\text { tumor } \\
\text { dimension }\end{array}$ & & 0.394 & 0.216 & & 0.147 & 0.279 \\
\hline$>3.5$ & $27 / 44$ & & & $9 / 16$ & & \\
\hline$<=3.5$ & $26 / 51$ & & & $6 / 20$ & & \\
\hline $\begin{array}{l}\text { Neoplasm } \\
\text { histologic grade }\end{array}$ & & $0.039 *$ & & & $0.004 *$ & \\
\hline G1 & $4 / 16$ & & - & $2 / 7$ & & - \\
\hline $\mathrm{G} 2$ & $31 / 52$ & & 0.606 & $6 / 20$ & & 0.998 \\
\hline G3 & $17 / 29$ & & 0.202 & $7 / 10$ & & 0.308 \\
\hline
\end{tabular}




\begin{tabular}{|c|c|c|c|c|c|c|}
\hline G4 & $1 / 2$ & & 0.757 & - & & - \\
\hline Pathologic stage & & 0.100 & & & 0.431 & \\
\hline Stage I & $0 / 1$ & & - & $0 / 1$ & & - \\
\hline Stage IA & $1 / 3$ & & 0.997 & $0 / 1$ & & 0.998 \\
\hline Stage IB & $3 / 10$ & & 0.998 & $0 / 2$ & & 0.998 \\
\hline Stage IIA & $5 / 13$ & & 0.998 & $3 / 7$ & & 0.998 \\
\hline Stage IIB & $43 / 70$ & & 0.998 & $11 / 24$ & & 0.998 \\
\hline Stage III & $1 / 2$ & & - & $0 / 1$ & & - \\
\hline Stage IV & - & & - & $1 / 1$ & & - \\
\hline
\end{tabular}

$401 \quad{ }^{*} \mathrm{p}<0.05$, statistically significant 


\begin{tabular}{lllll}
\hline \multicolumn{1}{l}{ Hazard } & CI & P value & Description \\
\hline Low Risk genes & & & & \\
\hline TTTY9B & 0 & $0.000-0.028$ & 0.0102 & $\begin{array}{l}\text { testis-specific transcript, Y-linked 9B } \\
\text { (non-protein coding) }\end{array}$ \\
\hline RNF121 & 0.001 & $0.000-0.260$ & 0.0142 & RING finger protein 121 \\
\hline FHAD1 & 0.006 & $0.001-0.051$ & $3.60 \mathrm{E}-06$ & Forkhead-associated domain-containing \\
& & & & protein 1 \\
\hline GTF2F2 & 0.007 & $0.000-0.516$ & 0.0235 & General transcription factor IIF subunit 2 \\
\hline ADAMTS19 & 0.009 & $0.001-0.113$ & 0.0002 & $\begin{array}{l}\text { A disintegrin and metalloproteinase with } \\
\text { thrombospondin motifs 19 }\end{array}$ \\
\hline LHFPL1 & 0.024 & $0.002-0.283$ & 0.0031 & $\begin{array}{l}\text { Lipoma HMGIC fusion partner-like 1 } \\
\text { protein }\end{array}$ \\
\hline DHDH & 0.05 & $0.013-0.191$ & $1.16 \mathrm{E}-05$ & Trans-1,2-dihydrobenzene-1,2-diol \\
& & & & dehydrogenase \\
\hline LOC256880 & 0.062 & $0.006-0.600$ & 0.0164 & \\
\hline SLC25A41 & 0.093 & $0.022-0.392$ & 0.001 & Solute carrier family 25 member 41 \\
\hline ZNF233 & 0.095 & $0.017-0.516$ & 0.0060 & Zinc finger protein 233 \\
\hline C6orf195 & 0.129 & $0.024-0.695$ & 0.0171 & \\
\hline PCDHA11 & 0.144 & $0.050-0.419$ & 0.00037 & Proto cadherin alpha-11 \\
\hline LOC401127 & 0.146 & $0.022-0.969$ & 0.0463 & \\
\hline TUBBP5 & 0.303 & $0.139-0.663$ & 0.0028 & tubulin beta pseudo gene 5 \\
\hline High risk genes & & & \\
\hline CRCT1 & 2.107 & $1.154-3.847$ & 0.0152 & Cysteine-rich C-terminal protein 1 \\
\hline MUC20 & 14.76 & $4.387-49.66$ & $1.37 \mathrm{E}-05$ & Mucin-20 \\
\hline RTP1 & 18.01 & $1.075-301.8$ & 0.0444 & Receptor-transporting protein 1 \\
\hline C10orf111 & 23.6 & $1.314-423.9$ & 0.0319 & \\
\hline SPACA5 & 23.83 & $1.821-311.7$ & 0.0156 & Sperm acrosome-associated protein 5 \\
\hline FZD10 & 26.54 & $5.142-136.9$ & $9.02 \mathrm{E}-05$ & Frizzled-10 \\
\hline PS0.05, & & &
\end{tabular}




\begin{tabular}{lllll}
\hline \multicolumn{1}{l}{ Hazard } & CI $(95 \%)$ & $\mathrm{p}$-value & Description \\
\hline \multicolumn{2}{l}{ Low Risk genes } & & & \\
\hline $\begin{array}{l}\text { SYS1- } \\
\text { DBNDD2 }\end{array}$ & 0.347 & $0.909-1.815$ & 0.0020 & \\
\hline NCRNA00167 & 0.231 & $0.978-1.719$ & 0.0015 & \\
\hline IRX5 & 0.473 & $0.282-1.185$ & 0.0012 & $\begin{array}{l}\text { Iroquois-class homeodomain protein } \\
\text { IRX-5 }\end{array}$ \\
\hline ZNF77 & 0.244 & $0.770-1.801$ & 0.0040 & Zinc finger protein 77 \\
\hline CATSPERG & 0.296 & $0.651-0.991$ & 0.0029 & Cation channel sperm-associated \\
& & & & protein subunit gamma \\
\hline High Risk genes & & & \\
\hline ZNF793 & 2.968 & $0.358-1.978$ & 0.0063 & Zinc finger protein 793 \\
\hline GBP6 & 1.744 & $0.342-1.207$ & 0.0011 & Guanylate-binding protein 6 \\
\hline FOSL1 & 2.306 & $0.9601-1.051$ & 0.0091 & Fos-related antigen 1 \\
\hline
\end{tabular}

$* \mathrm{p}<0.05$, statistically significant 
406 Table 4. Multivariate Cox regression analysis of prognosis index and clinical traits

\begin{tabular}{llll}
\hline $\begin{array}{l}\text { PC with Non- } \\
\text { diabetes }\end{array}$ & HR & CI & $\begin{array}{l}\text { Multivariate } \\
\text { P-value }\end{array}$ \\
\hline PI & 1.102 & $1.070-1.136$ & $2.68 \mathrm{e}-10^{*}$ \\
$\begin{array}{l}\text { Tumor Status } \\
\text { Number of lymph }\end{array}$ & 0.117 & $0.298-1.924$ & $0.0005^{*}$ \\
nodes positive by & & $0.907-2.783$ & 0.106 \\
he & & & \\
G2 & 2.103 & $0.187-5.400$ & 0.123 \\
G3 & 2.036 & $0.739-5.613$ & 0.169 \\
G4 & 2.215 & $0.257-19.087$ & 0.469 \\
\hline PC with Diabetes & & & \\
\hline PI & 1.212 & $1.108-1.327$ & $2.83 \mathrm{e}-05^{*}$ \\
Gender & 0.173 & $0.053-0.564$ & $0.004^{*}$ \\
G2 & 0.897 & $0.168-4.775$ & 0.898 \\
G3 & 5.310 & $0.892-31.616$ & 0.067 \\
\hline p & & & \\
\hline
\end{tabular}




\section{Number of figures: 4}

409 Figure 1. WPI analysis of the integrated gene-and-clinical model for 136 TCGA PC patients.

410 (A) Survival analysis in PC patient with non-diabetes. (B) WPI distribution in the TCGA PC cohort

411 without diabetes. The dash line represents the cutoff used to categorize patients into the low-risk

412 group or the high-risk group. (C) Survival analysis in PC patient with diabetes. (D) WPI

413 distribution in the TCGA PC cohort with diabetes.

414 Figure 2. Exchange gene biomarker to cross-validate in two groups.(A) Using gene biomarker 415 of PC with diabetes to test in PC with non-diabetes. (B) Using gene biomarker of PC with non416 diabetes to test in PC with diabetes

417 Figure 3. Kaplan-Meier curves and ROC curves for validation PC patients in GEO database. 418 (A)The gene biomarker can greatly classify PC patients into high-risk and low-risk groups $419(\mathrm{p}<0.001)$. (B)The AUC of ROC is 0.828 , which represent that the gene biomarker model is very 420 good.

\section{$421 \quad$ Figure 4.}

422 Gene signature validation in Pancreatic cancer from ICGC database. (A) High-risk and low-risk 423 groups showed significantly difference $(\mathrm{HR}=2.84$, $\mathrm{P}$-value $<0.001)$ in ICGC PC data. (B) ROC 424 curve showed gene signature performance well in 3 years in ICGC PC data.. 


\section{Supplementary File legend}

426 Figure S1. The Cross-validation error curve of PC with diabetes. The left vertical dotted line reveals the 427 partial likelihood deviance achieves its minimum lambda, which represents a fairly regularized model. The 428 right vertical dotted line indicates the most regularized model (ie, null model) with cross-validation error 429 within one standard deviation of the minimum. The numbers at the top of the figure indicate the number of 430 nonzero coefficients.

431 Figure S2. The Cross-validation error curve of PC with non-diabetes. The left vertical dotted line reveals 432 the partial likelihood deviance achieves its minimum lambda, which represents a fairly regularized model. The 433 right vertical dotted line indicates the most regularized model (ie, null model) with cross-validation error within 434 one standard deviation of the minimum. The numbers at the top of the figure indicate the number of nonzero 435 coefficients 
Figure 1

Survival analysis in pancreatic cancer patient with non-diabetes.

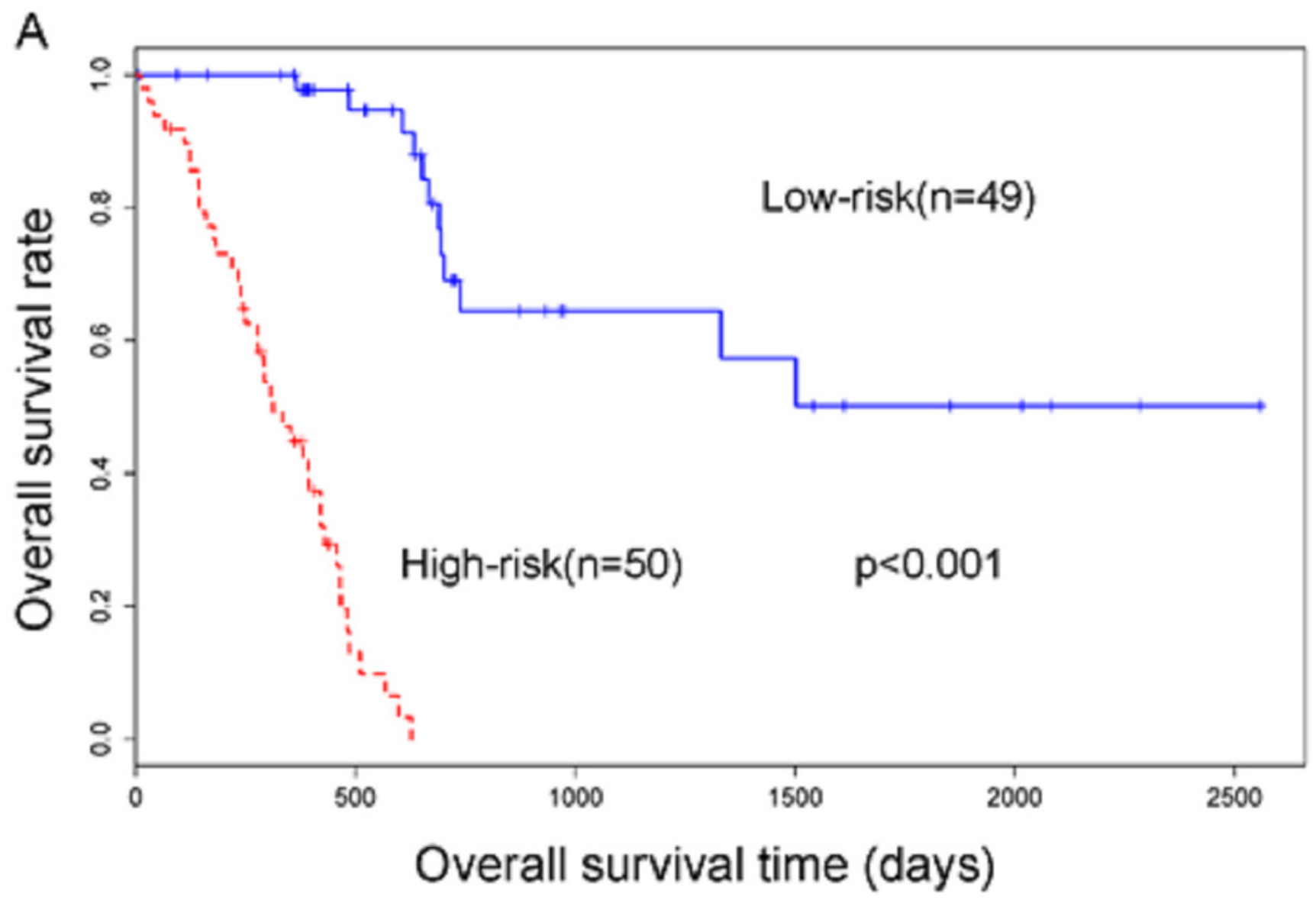


Figure 2

WPI distribution in the TCGA pancreatic cancer cohort without diabetes

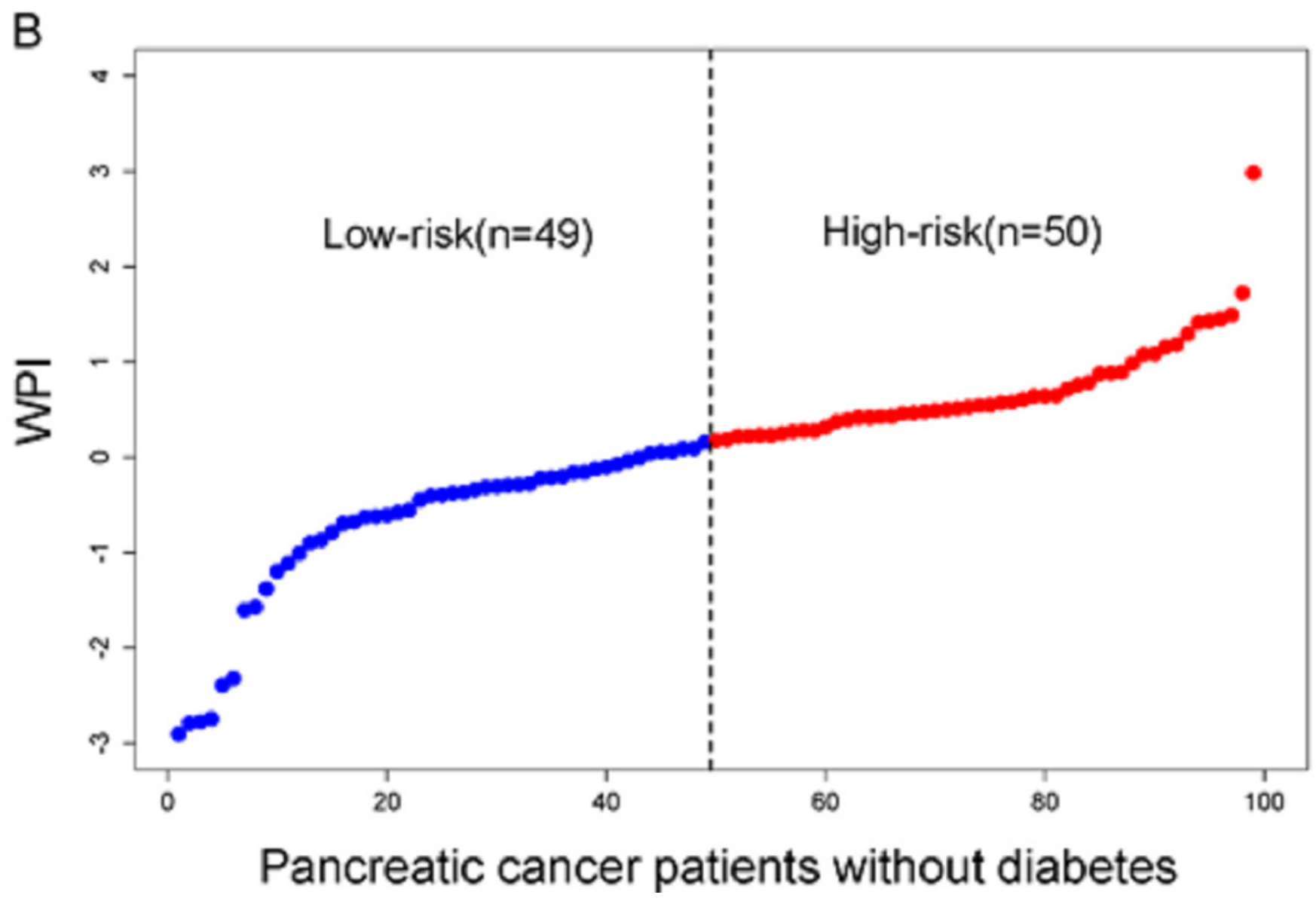


Figure 3

Survival analysis in pancreatic cancer patient with diabetes.

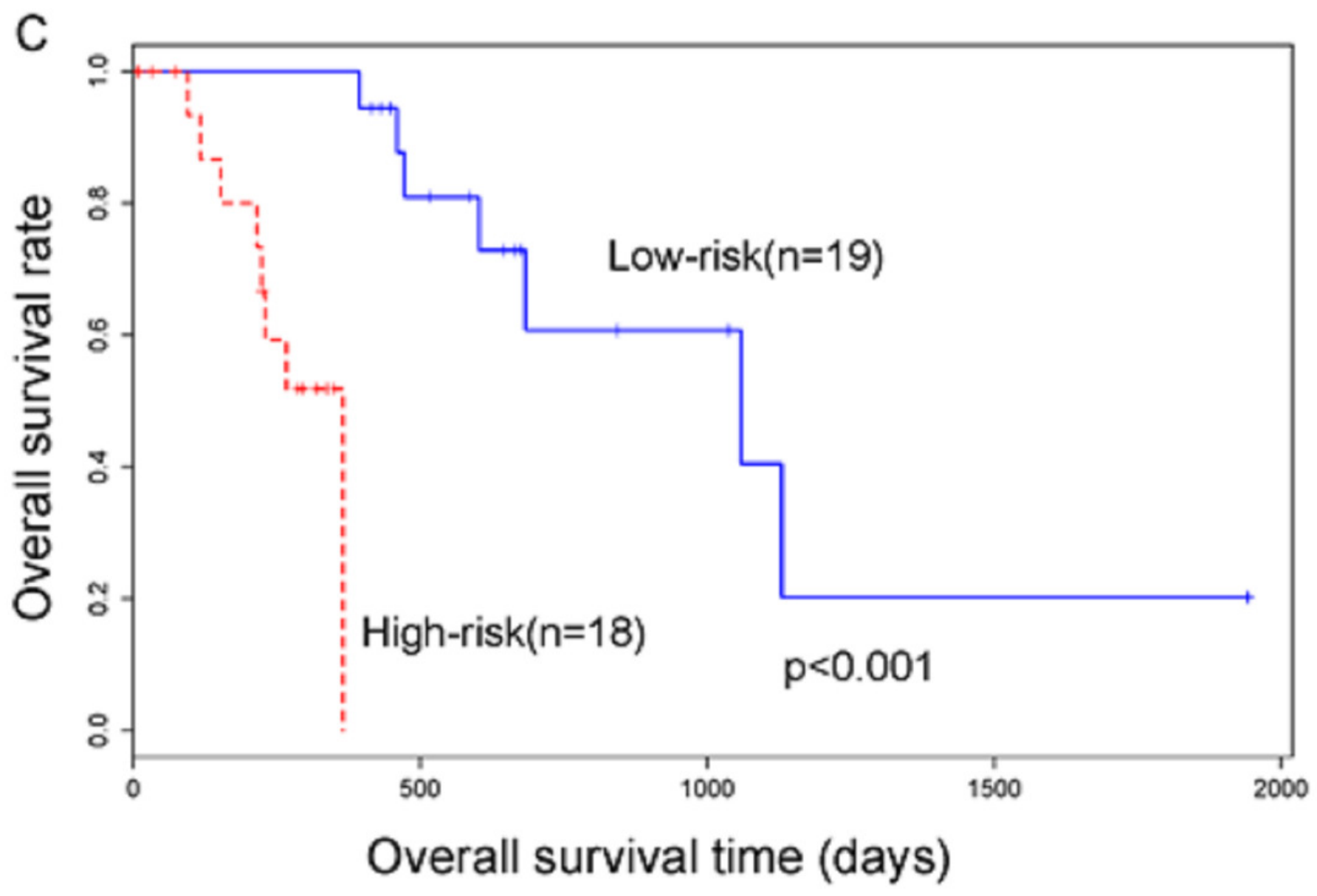


Figure 4

WPI distribution in the TCGA pancreatic cancer cohort with diabetes

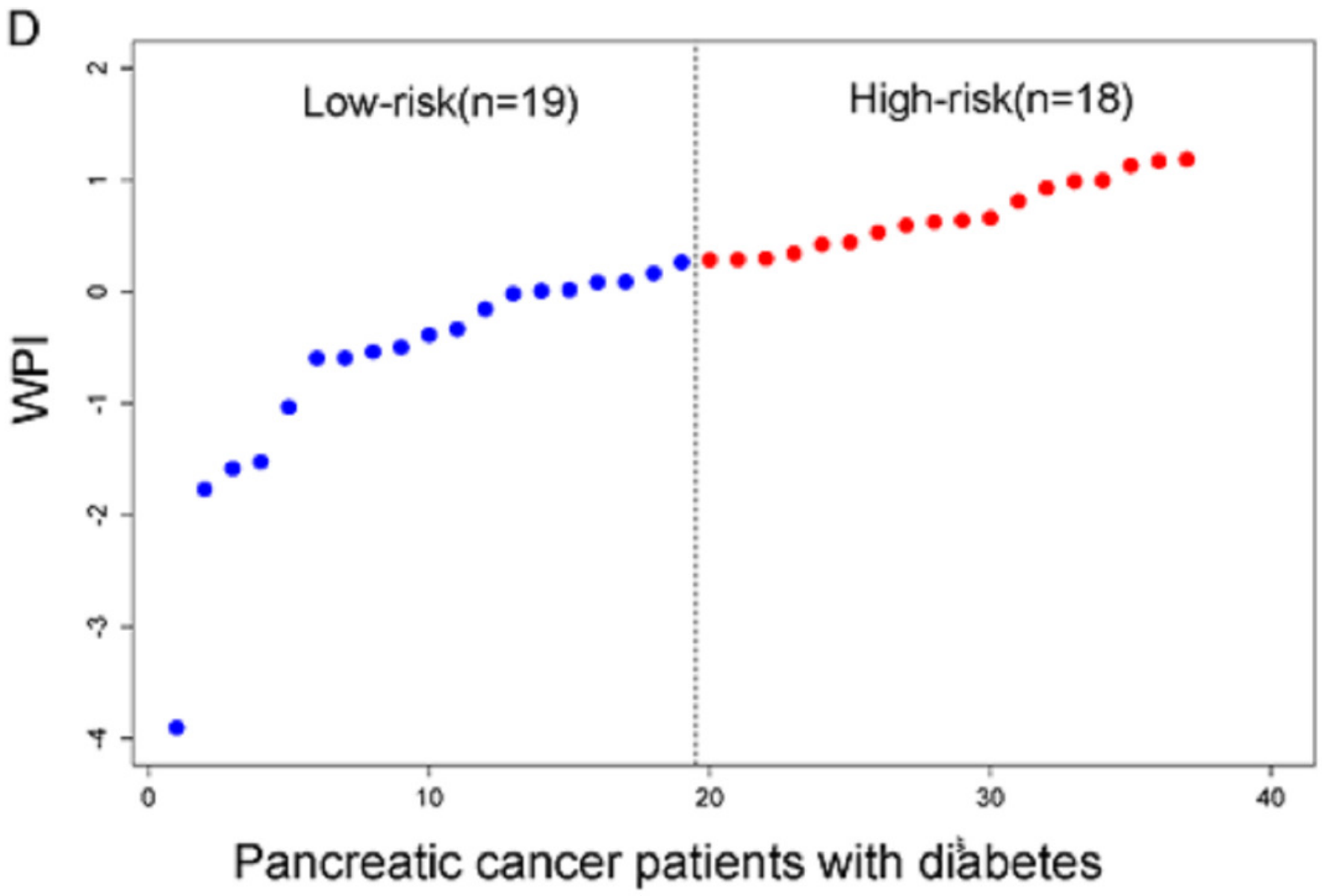


Figure 5

Using gene signature of PC with diabetes to test in PC with non-diabetes.

A

Gene signature of $\mathrm{PC}$ with diabetes validation in $\mathrm{PC}$ with non-diabetes

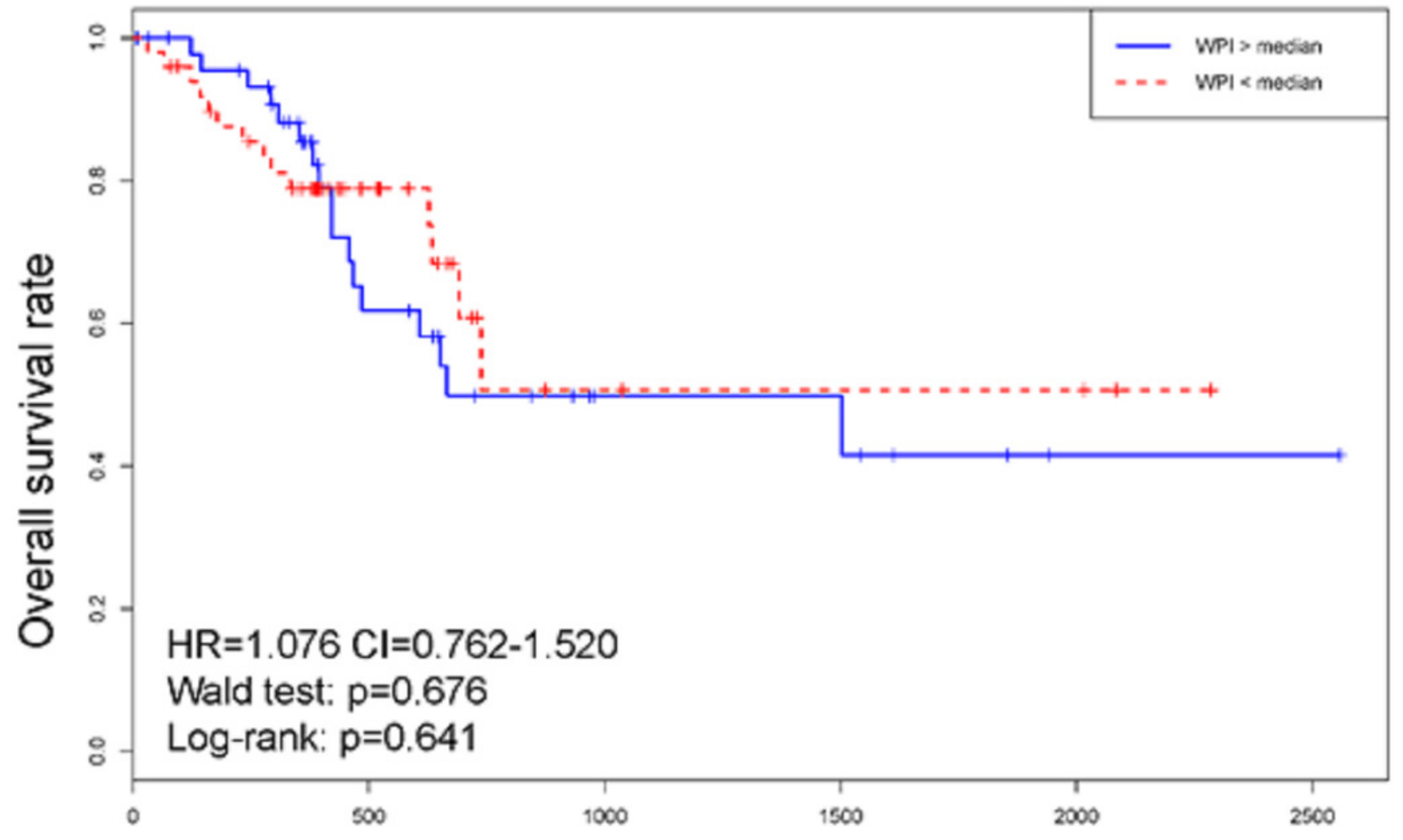

Overall survival time (days) 
Figure 6

Using gene signature of PC with non-diabetes to test in PC with diabetes

B Gene signature of $\mathrm{PC}$ with non-diabetes validation in $\mathrm{PC}$ with diabetes

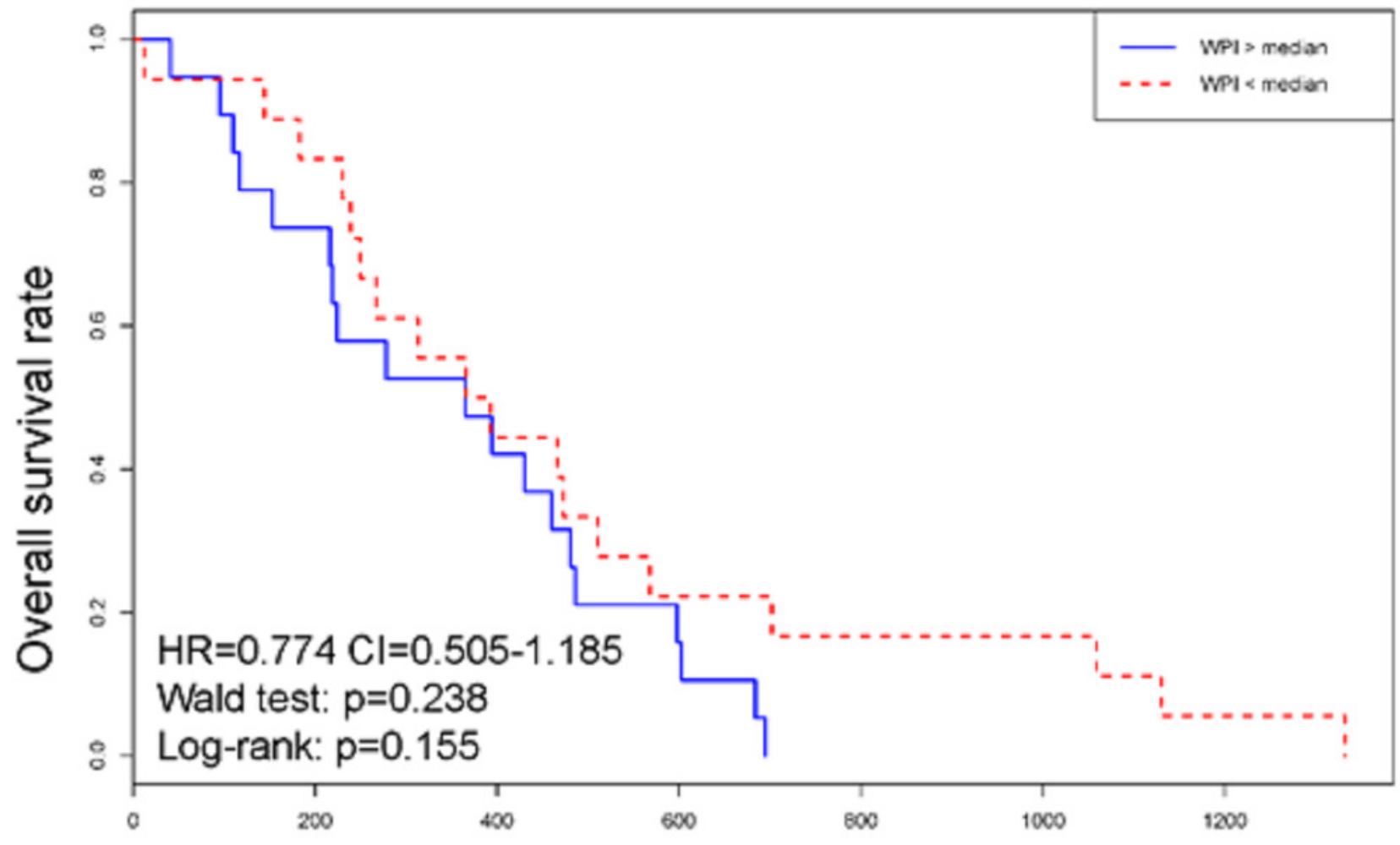

Overall survival time (days) 
Figure 7

The gene biomarker can greatly classifiy PC patients into high-risk and low-risk groups $(p<0.001)$

Risk and overall survival in GEO validation cohort

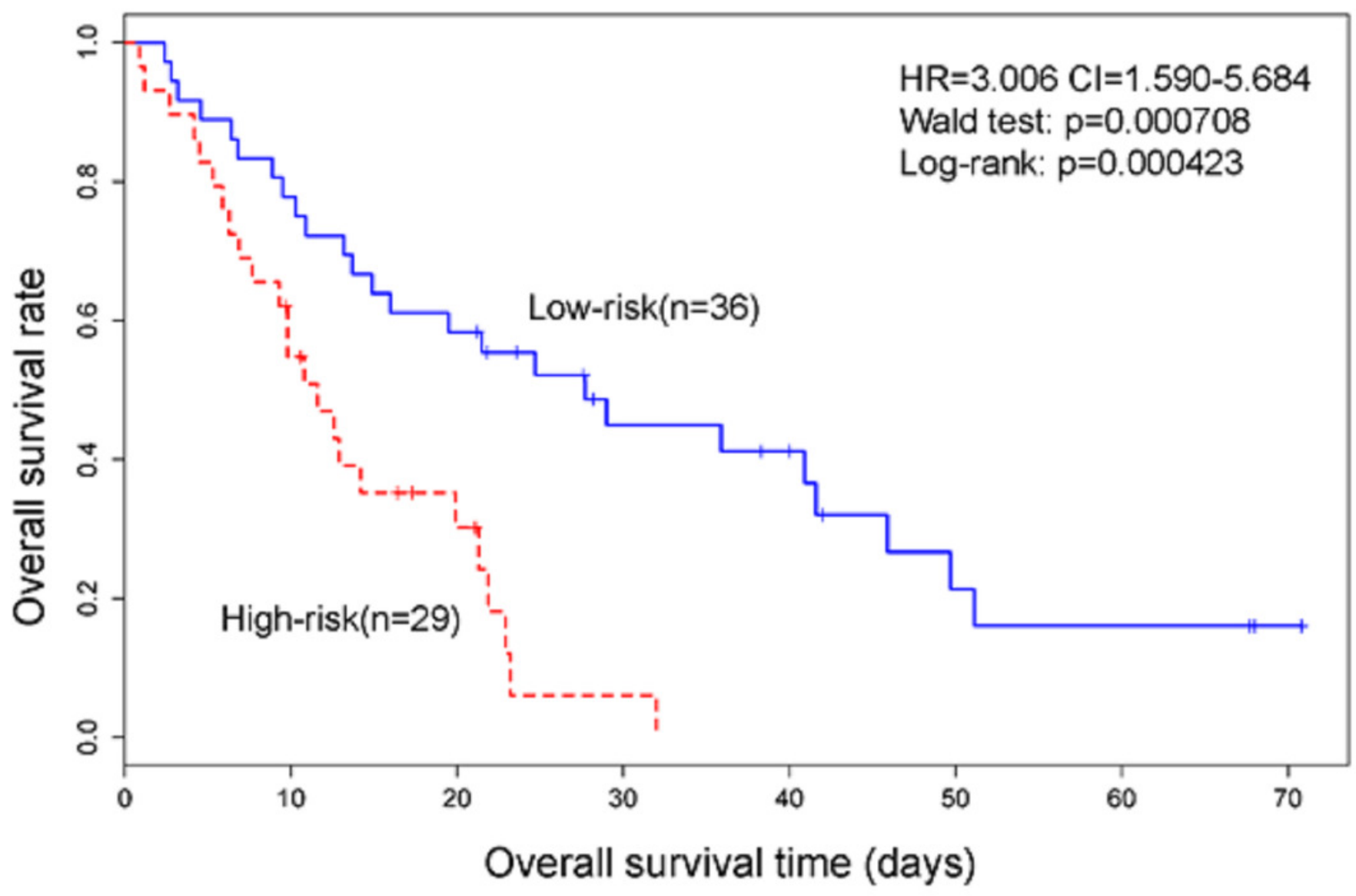


Figure 8

The AUC of ROC is 0.828 , which represent that the gene biomarker model is very good.

ROC in GEO validation cohort (Year $=3$ )

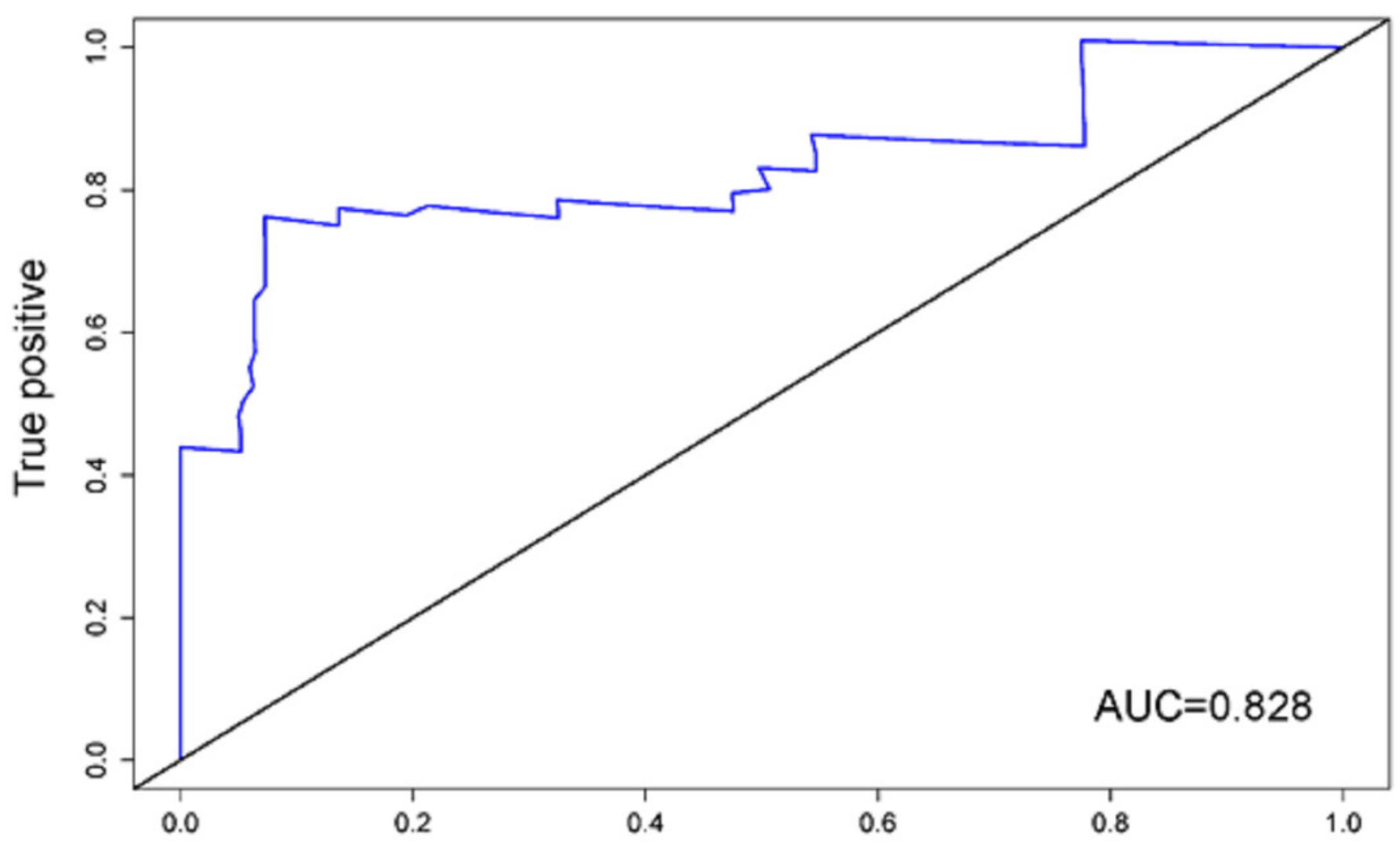

False positive 
Figure 9

The gene signature validated in ICGC database.
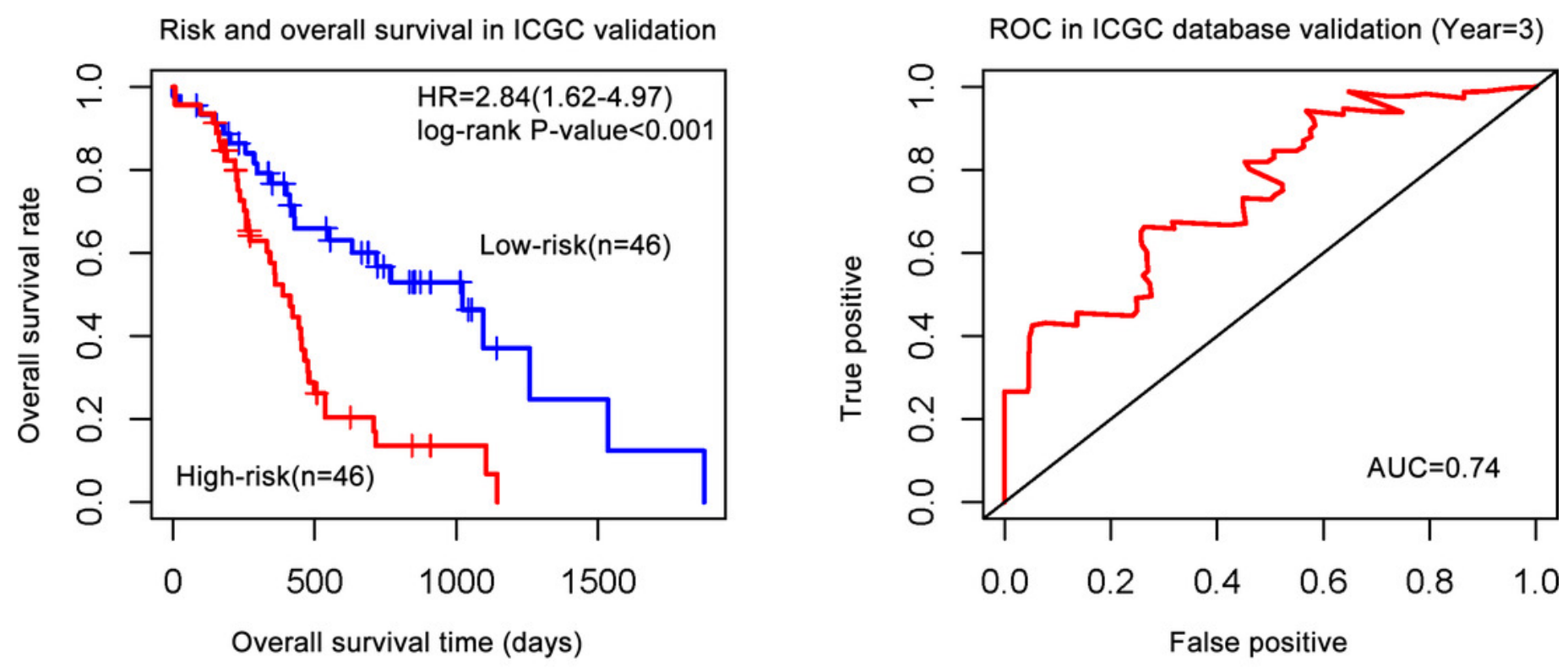


\section{Table $\mathbf{1}$ (on next page)}

Clinical traits in PC patients with non-diabetes and diabetes 


\begin{tabular}{|c|c|c|c|c|c|c|}
\hline \multicolumn{4}{|c|}{ Non-diabetes Pancreatic Cancer $(n=99)$} & \multicolumn{3}{|c|}{ Diabetes Pancreatic Cancer $(n=37)$} \\
\hline Factors & Death/patients & Log-rank & $\begin{array}{l}\text { Multivariat } \\
\text { e Cox P }\end{array}$ & Death/patients & Log-rank & $\begin{array}{l}\text { Multivariate } \\
\text { Cox P }\end{array}$ \\
\hline Age & & 0.051 & 0.496 & & 0.959 & 0.446 \\
\hline$<=64$ & $22 / 52$ & & & $7 / 16$ & & \\
\hline$>64$ & $31 / 47$ & & & $8 / 21$ & & \\
\hline Gender & & 0.402 & 0.172 & & $0.001 *$ & 0.340 \\
\hline Female & $27 / 50$ & & & $7 / 12$ & & \\
\hline Male & $26 / 49$ & & & $8 / 25$ & & \\
\hline Tumor Status & & $9.3 \mathrm{e}-06^{*}$ & $0.0004 *$ & & $0.005^{*}$ & 0.513 \\
\hline With Tumor & $42 / 57$ & & & $10 / 17$ & & \\
\hline Tumor Free & $6 / 35$ & & & $2 / 15$ & & \\
\hline Unknown & $7 / 7$ & & & $3 / 5$ & & \\
\hline Alcohol history & & 0.537 & 0.144 & & 0.599 & 0.638 \\
\hline Yes & $40 / 68$ & & & $10 / 27$ & & \\
\hline No & $12 / 39$ & & & $5 / 10$ & & \\
\hline Unknown & $1 / 2$ & & & - & & \\
\hline $\begin{array}{ll}\text { History of } \\
\text { chronic }\end{array}$ & & 0.597 & 0.998 & & 0.273 & 0.998 \\
\hline Yes & $4 / 8$ & & & $3 / 4$ & & \\
\hline No & $48 / 86$ & & & $10 / 31$ & & \\
\hline Unknown & $1 / 5$ & & & $2 / 2$ & & \\
\hline $\begin{array}{l}\text { Number of } \\
\text { lymph nodes } \\
\text { positive by he }\end{array}$ & & $0.003 *$ & 0.396 & & 0.480 & 0.533 \\
\hline$<3$ & $22 / 52$ & & & $7 / 20$ & & \\
\hline$>=3$ & $30 / 45$ & & & $8 / 16$ & & \\
\hline $\begin{array}{l}\text { Maximum } \\
\text { tumor } \\
\text { dimension }\end{array}$ & & 0.394 & 0.216 & & 0.147 & 0.279 \\
\hline$>3.5$ & $27 / 44$ & & & $9 / 16$ & & \\
\hline$<=3.5$ & $26 / 51$ & & & $6 / 20$ & & \\
\hline $\begin{array}{l}\text { Neoplasm } \\
\text { histologic grade }\end{array}$ & & $0.039 *$ & & & $0.004^{*}$ & \\
\hline G1 & $4 / 16$ & & - & $2 / 7$ & & - \\
\hline G2 & $31 / 52$ & & 0.606 & $6 / 20$ & & 0.998 \\
\hline G3 & $17 / 29$ & & 0.202 & $7 / 10$ & & 0.308 \\
\hline G4 & $1 / 2$ & & 0.757 & - & & - \\
\hline TNM stage & & 0.100 & & & 0.431 & \\
\hline
\end{tabular}




\begin{tabular}{lllll}
\hline Stage I & $0 / 1$ & - & $0 / 1$ & - \\
Stage IA & $1 / 3$ & 0.997 & $0 / 1$ & 0.998 \\
Stage IB & $3 / 10$ & 0.998 & $0 / 2$ & 0.998 \\
Stage IIA & $5 / 13$ & 0.998 & $3 / 7$ & 0.998 \\
Stage IIB & $43 / 70$ & 0.998 & $11 / 24$ & 0.998 \\
Stage III & $1 / 2$ & - & $0 / 1$ & - \\
Stage IV & - & - & $1 / 1$ & - \\
\hline
\end{tabular}

$2 * \mathrm{p}<0.05$, statistically significant

3

4 
Table 2 (on next page)

Gene biomarker in PC patients with non-diabetes 
Table 2 Gene signature in PC patients with non-diabetes

\begin{tabular}{|c|c|c|c|c|}
\hline & Hazard & $95 \% \mathrm{CI}$ & P-value & Description \\
\hline \multicolumn{5}{|c|}{ Low Risk genes } \\
\hline ТТТУ9В & 0 & $0.000-0.028$ & $0.0102 *$ & $\begin{array}{l}\text { testis-specific transcript, Y-linked 9B } \\
\text { (non-protein coding) }\end{array}$ \\
\hline$R N F 121$ & 0.001 & $0.000-0.260$ & $0.0142 *$ & RING finger protein 121 \\
\hline FHAD1 & 0.006 & $0.001-0.051$ & $<0.001 *$ & $\begin{array}{l}\text { Forkhead-associated domain-containing } \\
\text { protein } 1\end{array}$ \\
\hline$G T F 2 F 2$ & 0.007 & $0.000-0.516$ & $0.0235^{*}$ & $\begin{array}{l}\text { General transcription factor IIF subunit } \\
2\end{array}$ \\
\hline ADAMTS19 & 0.009 & $0.001-0.113$ & $0.0002 *$ & $\begin{array}{l}\text { A disintegrin and metalloproteinase } \\
\text { with thrombospondin motifs } 19\end{array}$ \\
\hline LHFPL1 & 0.024 & $0.002-0.283$ & $0.0031 *$ & $\begin{array}{l}\text { Lipoma HMGIC fusion partner-like } 1 \\
\text { protein }\end{array}$ \\
\hline $\mathrm{DHDH}$ & 0.05 & $0.013-0.191$ & $<0.001 *$ & $\begin{array}{l}\text { Trans-1,2-dihydrobenzene-1,2-diol } \\
\text { dehydrogenase }\end{array}$ \\
\hline LOC256880 & 0.062 & $0.006-0.600$ & $0.0164^{*}$ & \\
\hline$S L C 25 A 41$ & 0.093 & $0.022-0.392$ & $0.001 *$ & Solute carrier family 25 member 41 \\
\hline ZNF233 & 0.095 & $0.017-0.516$ & $0.0060^{*}$ & Zinc finger protein 233 \\
\hline C6orf195 & 0.129 & $0.024-0.695$ & $0.0171 *$ & \\
\hline РCDHA11 & 0.144 & $0.050-0.419$ & $<0.001^{*}$ & Proto cadherin alpha-11 \\
\hline LOC401127 & 0.146 & $0.022-0.969$ & $0.0463^{*}$ & \\
\hline TUBBP5 & 0.303 & $0.139-0.663$ & $0.0028 *$ & tubulin beta pseudo gene 5 \\
\hline \multicolumn{5}{|c|}{ High risk genes } \\
\hline CRCT1 & 2.107 & $1.154-3.847$ & $0.0152 *$ & Cysteine-rich C-terminal protein 1 \\
\hline MUC20 & 14.76 & $4.387-49.66$ & $<0.001^{*}$ & Mucin-20 \\
\hline$R T P 1$ & 18.01 & $1.075-301.8$ & $0.0444 *$ & Receptor-transporting protein 1 \\
\hline C10orf111 & 23.6 & $1.314-423.9$ & $0.0319 *$ & \\
\hline$S P A C A 5$ & 23.83 & $1.821-311.7$ & $0.0156^{*}$ & Sperm acrosome-associated protein 5 \\
\hline FZD10 & 26.54 & $5.142-136.9$ & $<0.001^{*}$ & Frizzled-10 \\
\hline
\end{tabular}

$3 * \mathrm{p}<0.05$, statistically significant 
Table 3 (on next page)

Gene biomarker in PC patients with diabetes 
1

2

Table 3 Gene signature in PC patients with diabetes

\begin{tabular}{lllll}
\hline & Hazard & $95 \% \mathrm{CI}$ & P-value & Description \\
\hline Low Risk genes & & & & \\
\hline SYS1-DBNDD2 & 0.347 & $0.909-1.815$ & $0.0020^{*}$ & \\
NCRNA00167 & 0.231 & $0.978-1.719$ & $0.0015^{*}$ & \\
IRX5 & 0.473 & $0.282-1.185$ & $0.0012^{*}$ & Iroquois-class homeodomain protein \\
& & & & $\begin{array}{l}\text { IRX-5 } \\
\text { ZNF77 }\end{array}$ \\
CATSPERG & 0.244 & $0.770-1.801$ & $0.0040^{*}$ & $\begin{array}{l}\text { Zinc finger protein 77 } \\
\end{array}$ \\
& 0.296 & $0.651-0.991$ & $0.0029^{*}$ & $\begin{array}{l}\text { Cation channel sperm-associated } \\
\text { protein subunit gamma }\end{array}$ \\
\hline High Risk genes & & & & \\
\hline ZNF793 & 2.968 & $0.358-1.978$ & $0.0063^{*}$ & Zinc finger protein 793 \\
GBP6 & 1.744 & $0.342-1.207$ & $0.0011^{*}$ & Guanylate-binding protein 6 \\
FOSL1 & 2.306 & $0.9601-1.051$ & $0.0091^{*}$ & Fos-related antigen 1 \\
\hline
\end{tabular}

$3 * \mathrm{p}<0.05$, statistically significant 


\section{Table 4(on next page)}

Multivariate Cox regression analysis of prognosis index and clinical traits 
1 Table 4. Multivariate Cox regression analysis of prognosis index and clinical traits

\begin{tabular}{llll}
\hline $\begin{array}{l}\text { PC with Non- } \\
\text { diabetes }\end{array}$ & HR & CI & $\begin{array}{l}\text { Multivariate Cox } \\
\text { P-value }\end{array}$ \\
\hline PI & 1.102 & $1.070-1.136$ & $2.68 \mathrm{e}-10^{*}$ \\
$\begin{array}{l}\text { Tumor Status } \\
\text { Number of lymph }\end{array}$ & 0.117 & $0.298-1.924$ & $0.0005^{*}$ \\
nodes positive by & & $0.907-2.783$ & 0.106 \\
he & & & \\
G2 & 2.103 & & \\
G3 & 2.036 & $0.187-5.400$ & 0.123 \\
G4 & 2.215 & $0.739-5.613$ & 0.169 \\
\hline PC with Diabetes & & $0.257-19.087$ & 0.469 \\
\hline PI & 1.212 & & \\
Gender & 0.173 & $1.108-1.327$ & $2.83 \mathrm{e}-05^{*}$ \\
G2 & 0.897 & $0.053-0.564$ & $0.004^{*}$ \\
G3 & 5.310 & $0.168-4.775$ & 0.898 \\
\hline
\end{tabular}

$2{ }^{*} \mathrm{p}<0.05$, statistically significant 